\title{
Using COMSOL Multiphysics Software to Model Anisotropic Dielectric and Metamaterial Effects in Folded-Waveguide Traveling-Wave Tube Slow-Wave Circuits
}

David P. Starinshak and Nathan D. Smith

Ohio Aerospace Institute, Brook Park, Ohio

Jeffrey D. Wilson

Glenn Research Center, Cleveland, Ohio 


\section{NASA STI Program . . . in Profile}

Since its founding, NASA has been dedicated to the advancement of aeronautics and space science. The NASA Scientific and Technical Information (STI) program plays a key part in helping NASA maintain this important role.

The NASA STI Program operates under the auspices of the Agency Chief Information Officer. It collects, organizes, provides for archiving, and disseminates NASA's STI. The NASA STI program provides access to the NASA Aeronautics and Space Database and its public interface, the NASA Technical Reports Server, thus providing one of the largest collections of aeronautical and space science STI in the world. Results are published in both non-NASA channels and by NASA in the NASA STI Report Series, which includes the following report types:

- TECHNICAL PUBLICATION. Reports of completed research or a major significant phase of research that present the results of NASA programs and include extensive data or theoretical analysis. Includes compilations of significant scientific and technical data and information deemed to be of continuing reference value. NASA counterpart of peer-reviewed formal professional papers but has less stringent limitations on manuscript length and extent of graphic presentations.

- TECHNICAL MEMORANDUM. Scientific and technical findings that are preliminary or of specialized interest, e.g., quick release reports, working papers, and bibliographies that contain minimal annotation. Does not contain extensive analysis.

- CONTRACTOR REPORT. Scientific and technical findings by NASA-sponsored contractors and grantees.

- CONFERENCE PUBLICATION. Collected papers from scientific and technical conferences, symposia, seminars, or other meetings sponsored or cosponsored by NASA.

- SPECIAL PUBLICATION. Scientific, technical, or historical information from NASA programs, projects, and missions, often concerned with subjects having substantial public interest.

- TECHNICAL TRANSLATION. Englishlanguage translations of foreign scientific and technical material pertinent to NASA's mission.

Specialized services also include creating custom thesauri, building customized databases, organizing and publishing research results.

For more information about the NASA STI program, see the following:

- Access the NASA STI program home page at http://www.sti.nasa.gov

- E-mail your question via the Internet to help@ sti.nasa.gov

- Fax your question to the NASA STI Help Desk at 301-621-0134

- Telephone the NASA STI Help Desk at 301-621-0390

- Write to: NASA Center for AeroSpace Information (CASI) 7115 Standard Drive Hanover, MD 21076-1320 
Using COMSOL Multiphysics Software to Model Anisotropic Dielectric and Metamaterial Effects in Folded-Waveguide Traveling-Wave Tube Slow-Wave Circuits

David P. Starinshak and Nathan D. Smith

Ohio Aerospace Institute, Brook Park, Ohio

Jeffrey D. Wilson

Glenn Research Center, Cleveland, Ohio

Prepared for the

Ninth International Vacuum Electronics Conference (IVEC 2008)

sponsored by the IEEE Electronic Device Society

Monterey, California, April 22-24, 2008

National Aeronautics and

Space Administration

Glenn Research Center

Cleveland, Ohio 44135 


\section{Acknowledgments}

This work was supported by the NASA Glenn Research Center’s Independent R\&D Fund.

Trade names and trademarks are used in this report for identification only. Their usage does not constitute an official endorsement, either expressed or implied, by the National Aeronautics and Space Administration.

Level of Review: This material has been technically reviewed by technical management.

Available from

NASA Center for Aerospace Information 7115 Standard Drive

Hanover, MD 21076-1320
National Technical Information Service 5285 Port Royal Road Springfield, VA 22161

Available electronically at http://gltrs.grc.nasa.gov 


\title{
Using COMSOL Multiphysics Software to Model Anisotropic Dielectric and Metamaterial Effects in Folded-Waveguide Traveling-Wave Tube Slow-Wave Circuits
}

\author{
David P. Starinshak and Nathan D. Smith \\ Ohio Aerospace Institute \\ Brook Park, Ohio 44142 \\ Jeffrey D. Wilson \\ National Aeronautics and Space Administration \\ Glenn Research Center \\ Cleveland, Ohio 44135
}

\begin{abstract}
The electromagnetic effects of conventional dielectrics, anisotropic dielectrics, and metamaterials were modeled in a terahertz-frequency folded-waveguide slow-wave circuit. Results of attempts to utilize these materials to increase efficiency are presented.
\end{abstract}

\section{Introduction}

COMSOL Multiphysics (ref. 1) is a versatile commercial software package that solves systems of coupled threedimensional partial differential equations. Thus it can be used to model physical phenomena in a wide range of applications including electromagnetics. With the finite element method of solution, it can easily model complex material properties that cannot readily be modeled with finite difference codes. For our interests in particular, it can solve for the electromagnetic fields in devices that include anisotropic dielectrics or metamaterials with negative values for electric permittivity and/or magnetic permeability.

We will confirm that COMSOL Multiphysics can accurately determine the dispersion and interaction impedance for slow-wave circuits. We will then show that it can be used to investigate electromagnetic effects of both conventional dielectrics and unconventional materials such as anisotropic dielectrics and metamaterials. In particular, we will show results of attempts to improve the design power and efficiency of a terahertz-frequency folded-waveguide slow-wave circuit.

\section{Background}

There is much interest in using vacuum electronic amplifiers in the terahertz regime of the electromagnetic spectrum because of their superior power and efficiency capabilities compared to solid state power amplifiers (SSPA's) at high frequencies (ref. 2). However, power and efficiency levels with conventional vacuum electronics devices are still quite low at these frequencies because of the small size of the circuit dimensions and high attenuation (ref. 3).

In attempts to reduce the attenuation and improve power and efficiency at terahertz frequencies, we modeled and investigated the effects of conventional dielectrics, anisotropic dielectrics, and metamaterials with negative values of electric permittivity and/or magnetic permeability (refs. 4 and 5) in a metallic folded-waveguide slow-wave circuit. The COMSOL Multiphysics finite element software package was utilized because its flexibility enables it to model material properties that are difficult to model with finite difference codes.

\section{Analysis and Results}

To test its accuracy, COMSOL Multiphysics's RF Module was used to compute the dispersion and interaction impedance for ferruleless and ferruled coupled-cavity slow-wave circuits. The agreement with experiment was comparable to that obtained previously with other software (refs. 6 and 7). It was then used to model the dispersion, interaction impedance, and attenuation for the folded-waveguide slow-wave circuit shown in figure 1 operating at a frequency of $0.4 \mathrm{THz}$. Figure 2 shows the computed surface current densities on the conducting waveguide walls for half of a geometric period. Because the current density and corresponding ohmic loss is strongest along the inside curves of the waveguide, we experimented with replacing the metal with nonconducting materials in these regions.

We first modeled the dielectric silicon on the inner curve surfaces. Although it would be difficult, in principle this structure could be fabricated with a dielectric-metal layered structure. At $0.4 \mathrm{THz}$, the computed attenuation dropped 45 percent, but unfortunately the interaction impedance dropped by 60 percent, resulting in a decrease in estimated circuit efficiency. We next investigated the effects of anisotropic dielectrics in which the permittivity is directionally dependent. However, scanning over the permittivity tensor components showed no improvement over the isotropic case. 


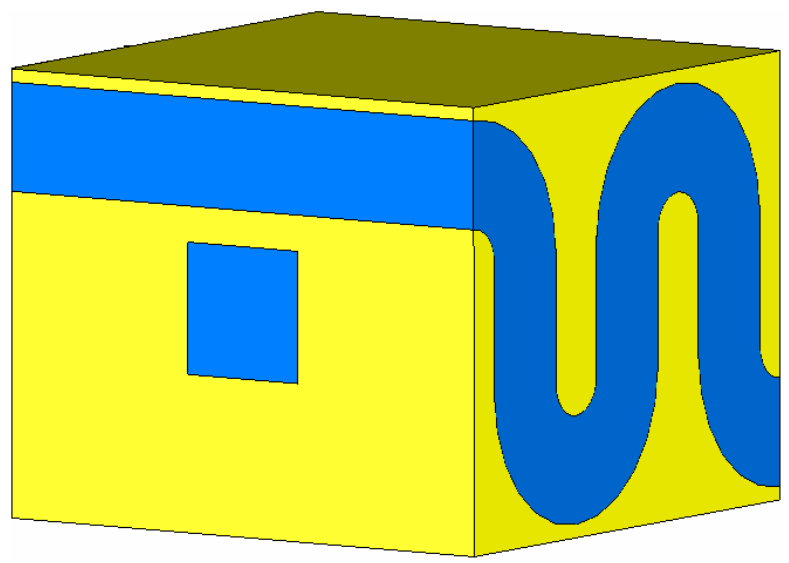

Figure 1.-Section of folded-waveguide slow-wave circuit. Electron beam passing through square aperture interacts with electromagnetic wave passing through serpentine waveguide.

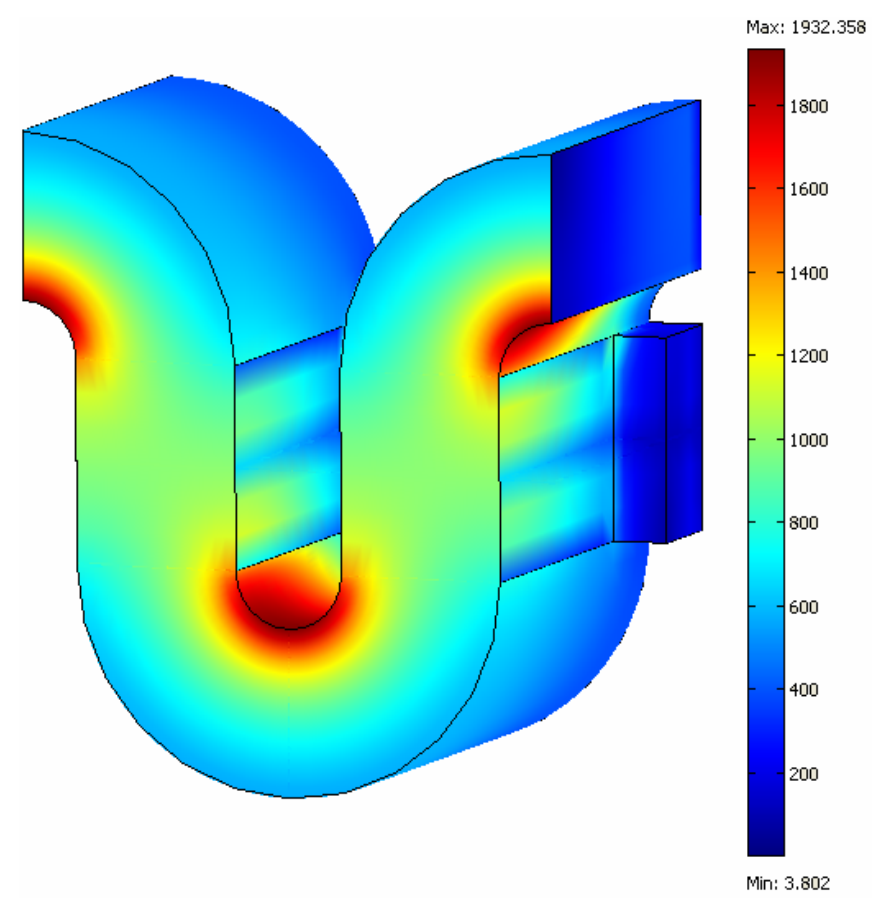

Figure 2.-Computed surface current densities for half of a geometric period of folded-waveguide slow-wave circuit.
Finally we investigated metamaterials. These engineered non-natural materials have been shown recently to exhibit effective negative values for permittivity and permeability at microwave frequencies (refs. 4 and 5). We did determine that the efficiency could be improved for small conductivity values when permittivity and permeability have opposite signs and small values. It is possible that future developments in metamaterial theory and nanofabrication could make such material characteristics possible in the future. However present metamaterials have high attenuation and there is as of yet no known method of fabricating such a hypothetical low-loss metamaterial.

\section{Conclusion}

We were not able to design for a significant improvement in computed power or efficiency by utilizing either conventional dielectrics, non-isotropic dielectrics, or existing metamaterials in terahertz folded-waveguide slow-wave circuit designs. Barring future major advances in metamaterial theory and nanofabrication, it appears that this is not a useful path toward efficiency and power improvement. However, we were able to show that COMSOL Multiphysics is a useful tool for investigating unconventional materials in electromagnetic devices. In the future, this modelling capability may be able to show that such materials can provide significant advantages in other applications.

\section{References}

1. http://www.comsol.com.

2. J. Booske, D. Whaley, W. Menninger, R. Hollister, and C. Armstrong, "Traveling-Wave Tubes," in Modern Microwave and Millimeter-Wave Power Electronics, R. Barker et al., eds. New York: Wiley-Interscience, chap. 4, 2005.

3. G. Scheitrum, "Microfabricated MVEDs," in Modern Microwave and Millimeter-Wave Power Electronics, R. Barker et al., eds. New York: Wiley-Interscience, chap. 7, 2005.

4. D. Smith, et al., "Composite Medium with Simultaneously Negative Permeability and Permittivity, Phys. Rev. Letters, May 1, 2000.

5. J. Wilson and Z. Schwartz, "Multifocal Flat Lens With LeftHanded Metamaterial,” Applied Physics Letters, Jan. 10, 2005.

6. D. Schroeder and J. Wilson. "Ferruleless Coupled-Cavity Traveling-Wave Tube Cold-Test Characteristics Simulated with Micro-SOS,” NASA TP-3306, Aug. 1993.

7. J. Maruschek, C. Kory, and J. Wilson. "Generalized ThreeDimensional Simulation of Ferruled Coupled-Cavity TravelingWave Tube Dispersion and Impedance Characteristics,” NASA TP-3389, Nov. 1993. 


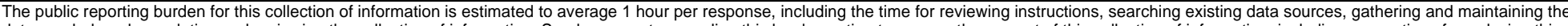

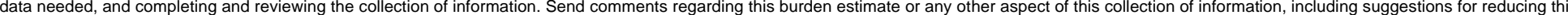

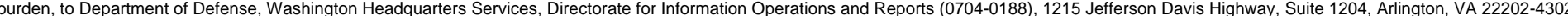

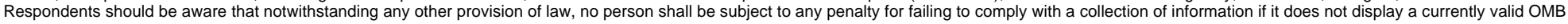
control number.

PLEASE DO NOT RETURN YOUR FORM TO THE ABOVE ADDRESS.

\section{REPORT DATE (DD-MM-YYYY) \\ 2. REPORT TYPE \\ 3. DATES COVERED (From - To)}

01-07-2008

Technical Memorandum

\section{TITLE AND SUBTITLE}

Using COMSOL Multiphysics Software to Model Anisotropic Dielectric and Metamaterial

Effects in Folded-Waveguide Traveling-Wave Tube Slow-Wave Circuits

5a. CONTRACT NUMBER

5b. GRANT NUMBER

5c. PROGRAM ELEMENT NUMBER

\section{AUTHOR(S)}

Starinshak, David, P.; Smith, Nathan, D.; Wilson, Jeffrey, D.

\section{5d. PROJECT NUMBER}

5e. TASK NUMBER

5f. WORK UNIT NUMBER

WBS 698671.01.03.45

\section{PERFORMING ORGANIZATION NAME(S) AND ADDRESS(ES)}

National Aeronautics and Space Administration

\section{PERFORMING ORGANIZATION} REPORT NUMBER

John H. Glenn Research Center at Lewis Field

E-16537

Cleveland, Ohio 44135-3191

\section{SPONSORING/MONITORING AGENCY NAME(S) AND ADDRESS(ES)}

National Aeronautics and Space Administration

Washington, DC 20546-0001

\section{SPONSORING/MONITORS ACRONYM(S) \\ NASA}

11. SPONSORING/MONITORING REPORT NUMBER

NASA/TM-2008-215267

\section{DISTRIBUTIONIAVAILABILITY STATEMENT}

Unclassified-Unlimited

Subject Category: 32

Available electronically at http://gltrs.grc.nasa.gov

This publication is available from the NASA Center for AeroSpace Information, 301-621-0390

\section{SUPPLEMENTARY NOTES}

\section{ABSTRACT}

The electromagnetic effects of conventional dielectrics, anisotropic dielectrics, and metamaterials were modeled in a terahertz-frequency folded-waveguide slow-wave circuit. Results of attempts to utilize these materials to increase efficiency are presented.

\section{SUBJECT TERMS}

Dielectrics; Circuits; Wave propagation; Anistropy; Permittivity; Finite element method

\section{SECURITY CLASSIFICATION OF:}

a. REPORT

$\mathrm{U}$

\begin{tabular}{|l|l}
\hline b. ABSTRACT & $\begin{array}{l}\text { c. THIS } \\
\text { PAGE } \\
\text { U }\end{array}$ \\
\hline
\end{tabular}

\section{LIMITATION OF} ABSTRACT

UU

18. NUMBER
OF
PAGES
8

19a. NAME OF RESPONSIBLE PERSON

STI Help Desk (email:help@sti.nasa.gov) 19b. TELEPHONE NUMBER (include area code) 301-621-0390 

